\title{
Microstructure and Properties of Ni-based and Fe- based coatings by Thermal Spray
}

\author{
Binfeng $\mathrm{He}$ \\ School of Physics and Mechanical \& Electronic Engineering, Xi'an University, Xi'an, 710065, Shanxi, China;Shanxi Key \\ Laboratory of Surface Engineering and Remanufacturing, Xi'an, 710065, Shaanxi, China
}

\begin{abstract}
Thermal spray is an effective method in the remanufacture process. In this paper, Ni-based and Fe-based powders were sprayed onto a steel substrate $40 \mathrm{Cr}$ using a thermal flame spray technology. The coatings were remelted by the heatronicheater. The morphology of the coatings was characterized by using scanning election microscope (SEM), energy dispersive spectrometer (EDS). The hardness and wear resistance of the coatings were investigated. The SEM results show that some of the porosities generated and coatings were comprised by molten and unmelted particles. Some of new phase were found after the remelting process in Ni-based coatings, and EDS analysis revealed that lots of chromium (Cr) element concentrated in the new phrase which maybe some of chromic compound generated during the remelting process. The microhardness results show that the Ni-based coating is harder than that of the Fe-based coating, and tribological result show that the friction coefficient of Ni-based coating is smaller than that of the Fe-based coating which gave an indirect evidence for the precipitated phase, which means the new phase is benefit to the coating.
\end{abstract}

Keywords-flame spray; ni-based powder; fe-based powder; microscopic structure; microhardness and wear resistance

\section{INTRODUCTION}

Coatings is one of the most effective strategies to protect the materials against corrosion and increase the wear resistance or a functional coating. It allows for development of materials with optimized surface behavior by using some of processable materials, and it can be seen form literatures that different coatings alternatives of car-bon steel, and different coatings alternatives of carbon steel, such as stainless steel [1]. Coatings could be generated by laser cladding, PVD, CVD, and thermal spray and soon on. In this work, thermal spray was used to deposit the wear resistance coatings.

Thermal spray technology is an advanced technology to deposit the coatings which used to support the development of the remanufacturing system [2] and be widely used in preparing high property coatings. The principle of thermal is to melt material feedstock (wire of powder) to accelerate the melt to impact on a substrate, the melt met-al would rapidly solidification and deposit on the substrate [3]. The coatings is one of the most effective strategies to protect materials against corrosion, high temperature resistance, thermal insulation and increase the wear resistance of materials which is helpful to the saving of materials and energy[4-6]. Thermal spray technologies were limited because of the shortcoming of the coating, but the fatal weakness is the low coating adhesion. Some of the post-fusing treatment, such as mid-temperature sinter coating [3], remelt (such as laser heating, high-frequency heating) and so on [7]. The results show that the properties of the coatings increased greatly [8].

\section{EXPERIMENTAL TECHNIQUES}

The substrate was a $40 \mathrm{Cr}$ steel with area dimensions of $\Phi 15 \mathrm{~mm} \times 20 \mathrm{~mm}$. The thicknesses of the top deposits were $0.4 \mathrm{~mm}, 0.5 \mathrm{~mm}$, and $0.6 \mathrm{~mm}$, respectively. The oxide skin was cleaned by mechanical lapping and the grinding wheel, then the rag were removed by abrasive papers, fi-nally, the samples were heated 300 degrees for 1 hour to re-move the greasy dirty. There are two different powders Ni60 and Fe60were used in this study, the compositions of the powders were presented in Table I and Table II. The powder particles were mainly spherical with the size of $45 \mu \mathrm{m}$.

The coatings were deposited by the flame spray (with a CP$100 \mathrm{P}$ coaxial airbrush), the working distance from air-brush to the substrate is $120 \mathrm{~mm}$, the movement velocity of airbrush is $800 \mathrm{~mm} / \mathrm{s}$, the offset of the airbrush is $4 \mathrm{~mm}$, the deposit angle is $90^{\circ}$, the flow rate of the oxygen is $530 \mathrm{~L} / \mathrm{min}$, and the acetylene is $800 \mathrm{~L} / \mathrm{h}$. Finally, the as-deposited coatings were remelted by the heatronicheater. The microstructures of coatings as well as the distribution of components were identified by scan electron micro-scope (SEM, JSM-6390A) equipped with energydispersive spectrometer (EDS). The samples for SEM observation were prepared through mechanical polishing and the following etching in natal with $4 \%$. The hardness profile on the coating surface was tested by a MH-5 Vikers microhardness tester at a load of $500 \mathrm{~g}$ and dwell time of $15 \mathrm{~s}$. A HT1000 ball-on-disk tribometer was used to evaluate the dry sliding friction and wear behavior. The disk was the specimen, while the counter-part ball was made of GCr15 steel (diameter of $5 \mathrm{~mm}$ ). The sliding tests were carried out with a load of $1000 \mathrm{~g}$, a contact sliding speed of $560 \mathrm{r} / \mathrm{min}$, the sliding radius of $3 \mathrm{~mm}$, and a sliding time of $40 \mathrm{~min}$.

TABLE I. CHEMICAL COMPOSITION OF THE NI60 POWDER, WT\%

\begin{tabular}{|c|c|c|c|c|}
\hline $\mathbf{C}$ & $\mathbf{S i}$ & $\mathbf{F e}$ & $\mathbf{C r}$ & $\mathbf{N i}$ \\
\hline $0.7-1.0$ & $3.5-5.0$ & $<8.0$ & $15-18$ & Balance \\
\hline
\end{tabular}

TABLE II. CHEMICAL COMPOSITION OF THE FE60 POWDER, WT\%

\begin{tabular}{|c|c|c|c|c|c|}
\hline $\mathbf{C}$ & $\mathbf{S i}$ & $\mathbf{B}$ & $\mathbf{N i}$ & $\mathbf{C r}$ & $\mathbf{F e}$ \\
\hline $0.8-1.2$ & $3.0-4.0$ & $3.8-4.2$ & $9-12$ & $16-18$ & Balance \\
\hline
\end{tabular}




\section{RESULTS AND DISCUSSION}

\section{A. Metallographic Analysis}

The micrographic of the coatings was studied by the scanning election microscope (SEM). And the cross-section and surface of coatings are shown in Figure I. The coatings is characterized by coating, precipitated phase, pores and impurity. It can be seen from Figure I (a) and (c) that there were much more granular particles in the Ni-based coating and some things new dissolved in the granular particles on the effect of remelting process. The Fe-based coating is laminated and some pores exist in the coating, as show in Figure I (b) (d).
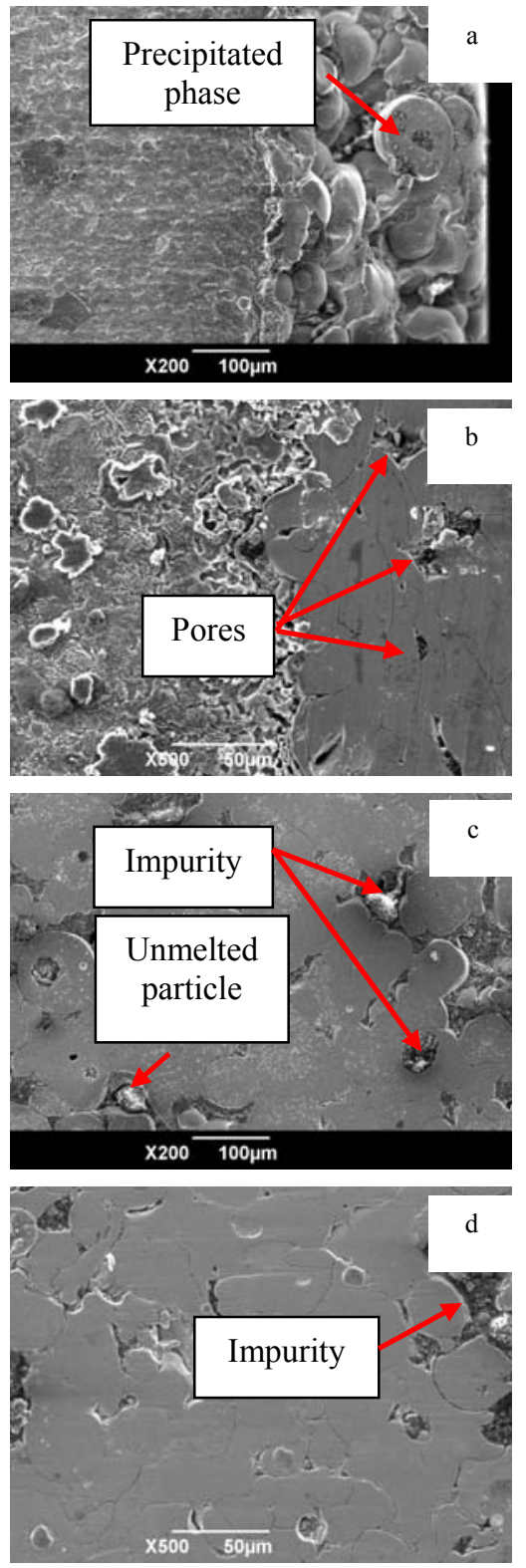

FIGURE I SEM IMAGE OF COATINGS (A) NI-BASED COATING (CROSS SECTION)(B) FE-BASED COATING (CROSS SECTION) (C) NI-BASED COATING (SURFACE) (D) FE-BASED COATING (SURFACE)
There are some impurities were found both in the Ni-based and Fe-based coatings, the EDS analysis result indicated that oxygen content in the places is more than $30 \%$, as show in Figure II. That's means, some oxide generated during the spray process on the effect of flame. What's more, some of the powders were not melting by the flame, so it can be seen some unmelted particles still exist in coating.

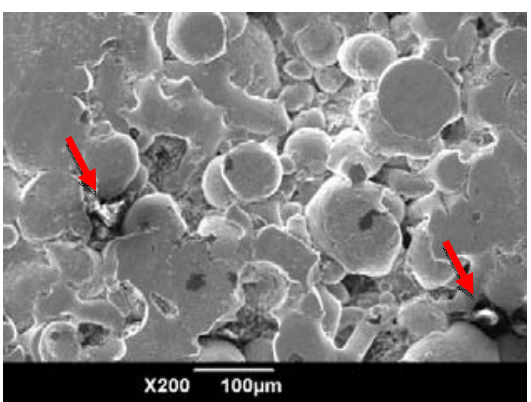

\begin{tabular}{|c|c|c|}
\hline Element & Mass(\%) & Atom(\%) \\
\hline C K & 46.93 & 61.09 \\
\hline Si K & 0.21 & 0.12 \\
\hline O K & 33.89 & 33.12 \\
\hline Cr K & 17.7 & 5.32 \\
\hline Fe K & 1.28 & 0.36 \\
\hline
\end{tabular}

FIGURE II . EDS ANALYSIS OF IMPURITY

The elements of coating were analyzed by energy dispersive spectrometer (EDS). The spectral line in interface obviously changed in Ni-based coating, some of elements almost discontinuous in interface. There are two reasons, for the first, the elements are indiffusible between coating and substrate; and the second, the scanning area is a trench. On the contrary, the elements distribution in Fe-based coating as show in Figure III (b), the spectral line in interface are continuous which means that the combination of the coating is much better but elements diffusion not very well. Contrast with (a) and (b) Fe-based coating is better than the Ni-based coating, is has started diffuse from coating to substrate in Fe-based coating.
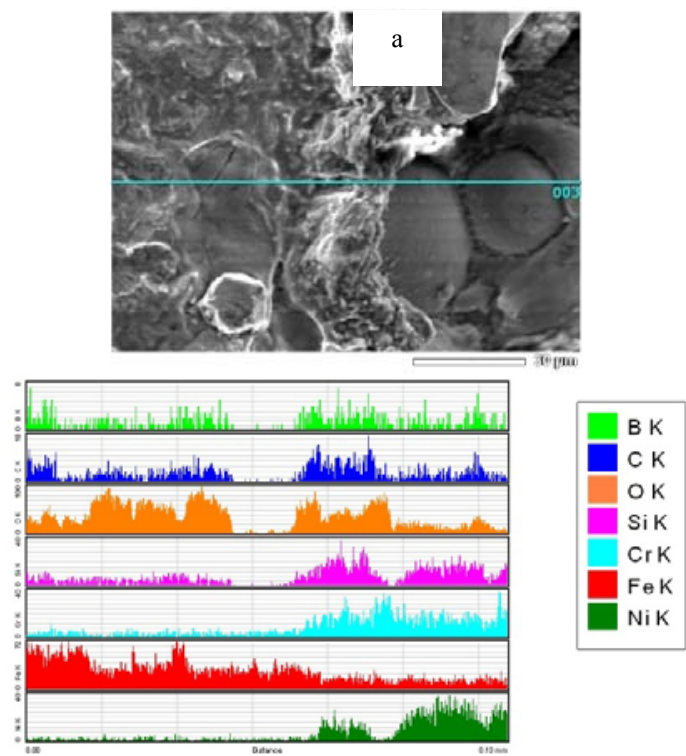


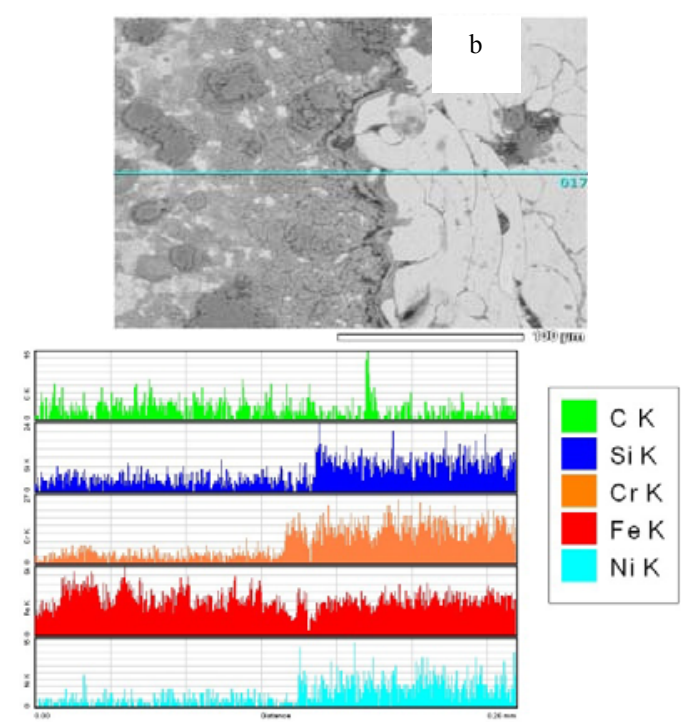

FIGURE III EDS ANALYSIS OF COATING(A) NI-BASED COATING(B) FE-BASED COATING

Post-remelting technology could improve the fatigue strengthen. Fracture toughness mathematical expression was described by Li Qiaolian et al. by using different ex-periment methods and parameters, but the formula did not mentioned the effect of spray processing and fatigue life [9]. Hiroyuki Akebono et al. had proved that the post-remelting have an important effect to the fatigue strengthen of coating [10].

In this work, high frequency remelting processing was used. The results show that there are some precipitated phase (granular constitution) generated after the remelting process, which was not found before the post-remelting. The EDS analysis result show that there were lots of chro-mium $(\mathrm{Cr})$ element in the precipitated phase, as shown in Figure IV; it means that the $\mathrm{Cr}$ element accumulated during the remelting process. That's means maybe a kind of chromic compound generated during the remelting process which would be benefit to the coating properties.

\section{B. Microhardness and Wear Resistance}

The microhardness of the coatings was detected by the microhardness tester. It can be seen from Figure $\mathrm{V}$ that the hardness increased with the increasing of coating thickness. But the hardness values changed unconspicuous because of the little variation of the thickness. Obviously, the Ni-based coating exhibits a significantly higher hardness than the Febased coating, in which provides evidence that the precipitated phase after the remelting process is benefit to the properties of Ni-based coatings.

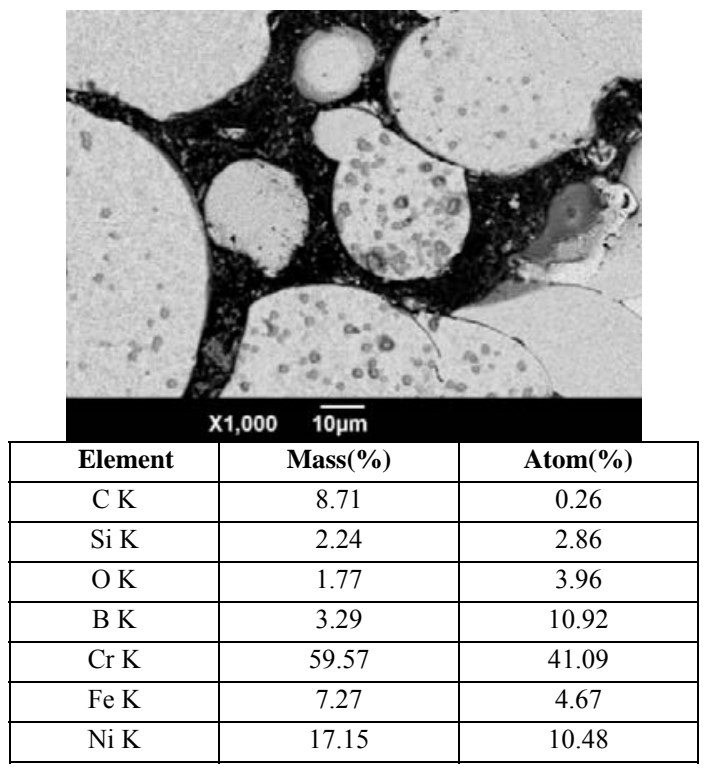

FIGURE IV SEM IMAGE OF PRECIPITATED PHASE AND THE EDS RESULT OF NI-BASED COATING

The dry sliding friction and abrasive resistance of the coatings were evaluated in ball-on-disk tribometer. The variations of friction coefficient with sliding time of the coatings under dry sliding test condition are shown in Figure VI. Obviously, the friction coefficient value of the Ni-based coating around approximately 0.55 , and the Fe-based coating around approximately 0.75 . The friction coefficient value of the Ni-based coating is much less than that of the Fe-based coating. This can be attributed to the precipitated phase which generated during the post-remelting process. The precipitated phase retain at the sliding surface of the Ni-based coating reducing the metal to metal contact and resisted the amount of plastic deformation in the substrate.

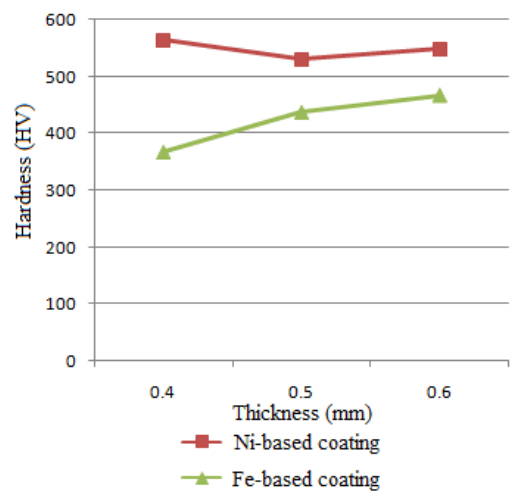

FIGURE V MICROHARDNESS OF THE COATINGS 


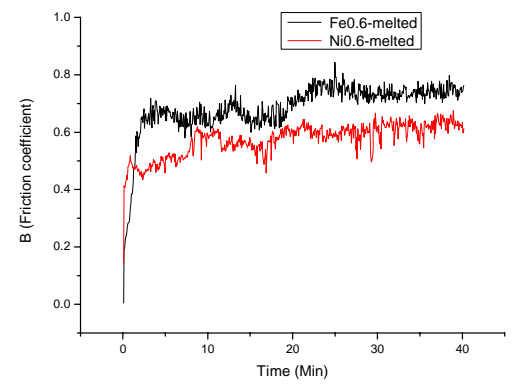

FIGURE VI FRICTION COEFFICIENT OF THE COATINGS

Worn surface morphologies were examined to clarify their wear behavior during dry frictional wear condition, as can be seen in Figure VII. Figure VII (a) shows the Ni-based coating, it's clearly that the main wear mechanisms of Ni-based coating is abrasive wear, and there can be seen some slight scratches along the sliding direction, and it's not found any kind of crack on the worn surface. In contrast, the trace of adhesive wear has been detected on the Fe-based coating. For this coating, the wear track exhibited a larger amount of material removal from the wear area. Some fracturing of lamellae can be identified. The loss of coating materials remained in the friction surface which accelerated the abrasion of the Fe-based coating. On the contrary, high hardness of Ni-based coating makes it very difficult to be ploughed during the dry sliding wear, which mainly caused by the precipitated phase.
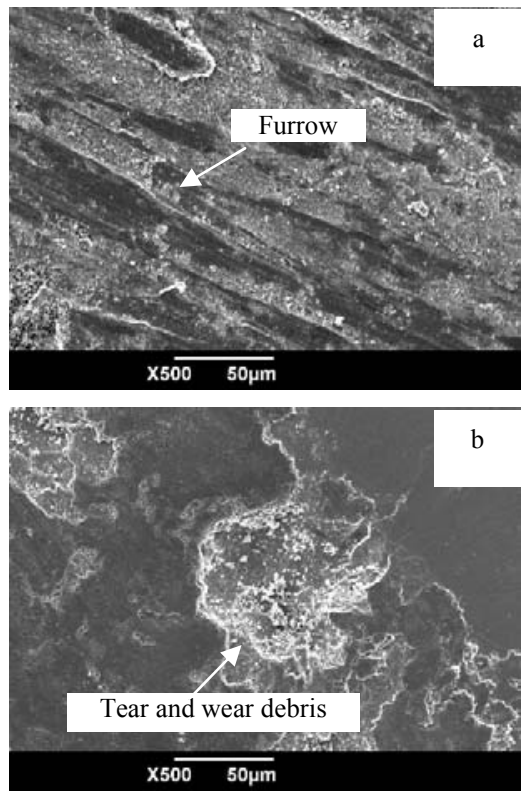

FIGURE VII SEM MICROGRAPHS SHOWING THE WORN SURFACE MORPHOLOGIES: (A) NI-BASED COATING AND (B) FE-BASED COATING

\section{CONCLUSIONS}

The results of the present study on the flame sprayed Nibased and Fe-based coatings can be summarized:
(1) The porosity of Fe-based coating is more than Ni-based coating.

(2) The stratified structures were obtained when molten drop deposited on the substrate. Some of impurities also generated because of the lower flying speed of the deposits.

(3) EDS results show that elements were hardly diffusion between coating and substrate. But the elements distribution in Fe-based coating is much better than in Ni-based coating.

(4) Precipitated phase were found in Ni-based coating, and the EDS analysis results show lots of $\mathrm{Cr}$ content which maybe a kind of chromic compound, and the micro hard-ness gave a positive evidence to validate that the compound is benefit to the coating.

(5) Tribological result show that the friction coefficient of Ni-based coating is smaller than that of the Fe-based coating which gave an indirect evidence for the precipitated phase.

\section{ACKNOWLEDGMENT}

This research is supported by Science and Technology planning project of Xi'an (CXY1352WL18) and the Natural Science Research Project from the Education Department of Shaanxi (14JK2138).

\section{REFERENCES}

[1] Bradai Mohand Amokrane, Sadeddine Abdelhamid, Mouadji Youcef, et al. Microstructure and Mechanical Properties of Ni-Based Thermal Spray Coating Deposited by Flame Spaying. Metallurgical and Materials Transactions B, Vol.42B, pp. 932-938, 2011.

[2] ZHANG Wei, GUO Yongming, CHEN Yongxiong. Applications and future development of thermal spraying technologies for remanufacturing engineering. China Surface Engineering, Vol.24 (6), pp. 1-10, 2011.

[3] Hiroshi Katanoda, Kazuyasu Matsuo. Analysis of particle behavior in high-velocity oxy-fuel thermal spraying process. J. of thermal science, Vol.12 (3), pp. 279-282, 2003.

[4] JIN Guo, XU Binshi, WANG Haidou, et al. Microstructure and wear resistance of electro-thermal explosion sprayed satellite coating used for remanufacturing. J. CENT. SOUTH UNIV. TECHNOL, Vol.12(2), pp. 207-210, 2005

[5] LI Xue-bing, QIU Changjun, WANG Shaoli, et al. Friction and Wear Characteristic of Thermal-sprayed WC-Co Mid-temperature Sintered Coating. Hot working technology, Vol.35(6), pp. 6-7, 2006.

[6] HUA Shaochun, WANG Hangong, WANG Liuying, et al. Development on thermal spray technology. Heat treatment of metals, Vol.33(5), pp. 82-87, 2008.

[7] ZHAO Zhiping, LI Xinyong, LI Youtang,et al. Effect of different postfusing treatment on fatigue strengthen and lifetime of thermal spraycoated components with cobalt-based powered alloy. Journal of Lanzhou University of Technology, Vol.37 (4), pp. 34-37, 2011.

[8] Z. Zhou, L. Wang, D.Y. He, et al. Microstructure and wear resistance of Fe-based amorphous metallic coatings prepared by HVOF thermal spraying. Journal of Thermal Spray Technology, Vol.19 (6), pp. 12871293, 2010.

[9] Li Qiaolian, Zhang Kun, Zhang Kai et al. Three point reverse bending test of interfacial fracture toughness on thermal spraying coating. Heat treatment of metal, Vol.35(1), pp. 114-116, 2010.

[10] Hiroyuki Akebono, Jun Komotori, Masao Shimizu. Effect of coating microstructure on the fatigue properties of steel thermally sprayed with Ni-based self-fluxing alloy. International journal of fatigue, (30), pp. 814-821, 2008. 